\title{
Mechanical properties of High and Very High Steel at elevated temperatures and after cooling down
}

\author{
Chrysanthos Maraveas ${ }^{1 *}$, Zacharias C. Fasoulakis ${ }^{2}$ and Konstantinos Daniel Tsavdaridis ${ }^{3}$
}

\begin{abstract}
High-strength steels (HSS) are produced using special chemical composition or/and manufacturing processes. Both aspects affect their mechanical properties at elevated temperatures and after cooling down, and particularly the residual strength and the ductility of the structural members. As HSS equates the design of lighter structural elements, higher temperatures are developed internally compared to the elements designed with conventional carbon steel. Therefore, the low thickness members, along with the severe effect of high temperature on the mechanical properties of the HSS, constitute to the increased vulnerability of such structures in fire. Moreover, the re-use and reinstatement of these structures are more challenging due to the lower residual mechanical properties of HSS after the cooling down period. This paper presents a review of the available experimental studies of the mechanical properties of HSS at elevated temperatures and after cooling down. The experimental results are collected and compared with the proposed material model (reduction factors) of EN1993-1-2. Based on these comparisons, modified equations describing the effect of elevated temperatures on the mechanical properties of HSS are proposed. Also, the post-fire mechanical properties of HSS are examined. A comprehensive discussion on the effect of influencing parameters, such as manufacturing process, microstructure, loading conditions, maximum temperature, and others is further explored.
\end{abstract}

Keywords: Mechanical properties, High strength steel, Elevated temperatures, Post-fire residual strength

\section{Introduction}

High (HSS) and very high strength (VHSS) steels have gained considerable attention in recent years. Increased construction demands impose the need of improved material properties. HSS contributes to reduced crosssectional area, resulting in lighter structures (or greater strength to weight ratio), greater clearance heights and easier fabrication and inspection. These reasons explain why HSS has been preferred to a great extent in bridge engineering and high rise buildings. Additionally, the use of VHSS has been recently introduced in civil engineering applications, while it has already been widely used in the automotive industry, due to its high tensile strength and energy absorption (Azhari et al., 2015).

Hitherto, there is some research activity in investigating the mechanical properties of high-strength steel under fire conditions and post-fire. However, given that notable variances between the experimental results and the design standards have been observed, studies that combine these findings are yet limited in the literature. This paper, firstly, presents a short review of the most significant experimental studies, describing the main aspects as well as relevant, important observations for each one. In addition, the key role factors influence the mechanical properties of structural steel at elevated temperatures and after cooling down are summarized. Subsequently, following a proper classification the test data recordings are comprehensively illustrated in a graphical form and compared with the existed design codes. Finally, new simplified models are presented, predicting the mechanical properties of high strength steels in fire and post-fire conditions.

* Correspondence: c.maraveas@maraveas.gr

'University of Liege, Liege, Belgium

Full list of author information is available at the end of the article 


\section{Literature review}

The need of use for high strength steel is highlighted by Bjorhovde (2010), by discussing the performance demands and the available steel grades productivity. The historical development of the yield strength of structural steel is schematically illustrated in Fig. 1, based on Schröter (2003, 2006). Schröter notes that although older productions of VHSS were observed brittle, improved manufacturing processes nowadays make them very competitive materials for structural use. The updated figure illustrates the extents of mild, high and very high strength structural steels according to the literature and the most used standards (in terms of nominal yield strength). The present work follows this protocol for the following discussion.

As it is already known, most of the high and very high strength steel grades derive their strength by quenching, while ductility is provided by subsequent tempering. In the recent study by Qiang et al. (2016), no brittle failure has been recorded for stress levels up to $1000 \mathrm{MPa}$, whilst necking characteristics have appeared for all specimens before failure. Especially for HSS (i.e. yield stress between 355 and $700 \mathrm{MPa}$ ), excellent toughness and weldability properties are acquired through rolling procedures at relatively low temperatures. Since 2006, general recommendations for the welding of VHSS are available by welding institutes, as it was identified by Pijpers (2011). On the other hand, during a fire event, the attained temperatures coincide with the tempering temperature, resulting in further decrease of the strength. The aforementioned issues are thoroughly addressed in the following section.

\section{Studies on mechanical properties}

The sequence of the studies reviewed herein are presented as follows. Firstly, significant works which addressed the experimental investigation of high and very high structural steel are included. Subsequently, several studies highlight the sensitivity of some parameters (such as strain rate, pre-damage, highest attained temperature, manufacturing process, and residual stresses) on the mechanical properties. At last, the review is focused on how different microstructure and thermal properties affect HSS and VHSS material properties.

Chen et al. (2006) were among the first researchers who addressed the performance of high strength steel at elevated temperatures. Firstly, the nominal yield stress ranges defining the high-strength steel, according to several standards, are noted. The experimental investigation involved mild and high strength steel using steady and transient-state test methods. The results revealed that HSS differentiation from the mild steel is obvious for temperatures above $500{ }^{\circ} \mathrm{C}$.

An important discovery by Qiang et al. (2016) is related the failure of $\mathrm{S} 960$ grade steel, which is observed from the transient state fire tests to reach its nominal yield stress for temperatures up to $400{ }^{\circ} \mathrm{C}$. In comparison with the design standards, a good relation is observed for Eurocode 3 (2005) and AISC (2010) only for the elastic modulus prediction. The investigation of other mechanical properties obtained from test results has shown no satisfactory compliance with the existing guidelines, i.e., European (EN 1993-1-2, 2005 and EN 1993-1-12, 2007), American (AISC (American Institute of Steel Construction), 2010), Australian (AS (Australian Standard), 2012) and British Standards (BS (British Standard), 1998) for steel structures. Therefore, it was considered necessarily to derive new recommendations for high strength steel grades.

Similar behaviour of the tested quenched and tempered S960 with the corresponding results of Outinen (2007)

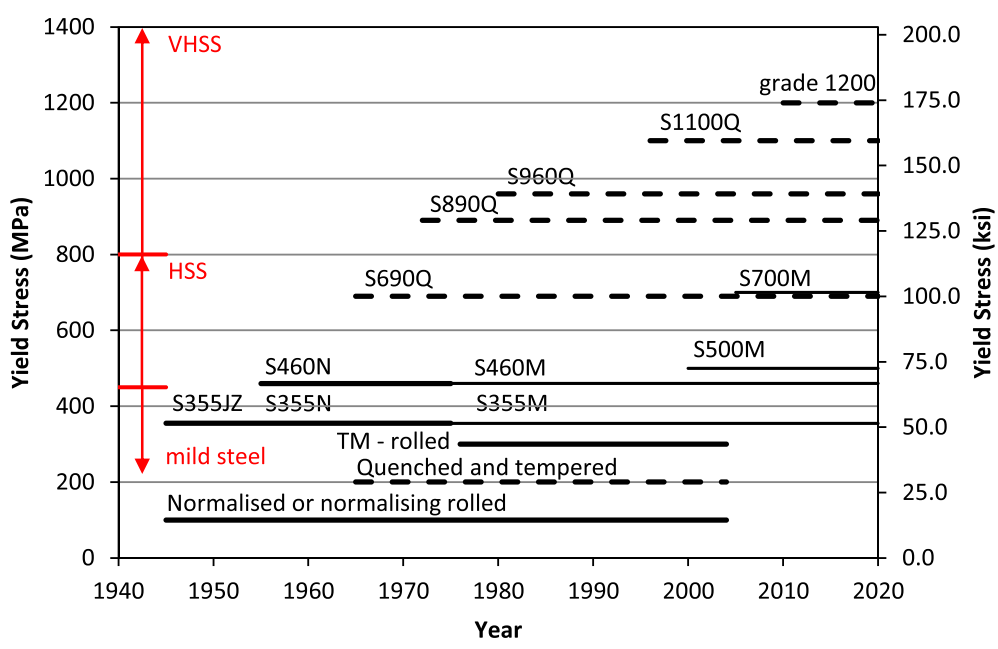

Fig. 1 Historical development of rolled steel products; based on Schröter $(2003,2006)$ 
and Qiang et al. (2012a, b), has been observed by Zhao and Chiew (2013). The specificity of the air cooling conditions has been also noted; the formulation of rust was not allowed during the experiment, consequently, the exact fire conditions could not be simulated.

The mechanical properties of VHSS both at elevated temperatures (up to $600{ }^{\circ} \mathrm{C}$ ) and after cooling down at ambient temperature are observed by Azhari et al. (2015) for specimens taken from hollow tubular sections and compared with corresponding ones from mild steel and high strength steel. The results showed that contrary to mild and high strength steel, the post-fire mechanical properties of VHSS are significantly reduced for temperatures up to $600{ }^{\circ} \mathrm{C}$. The variation of energy absorption, after heated and cooled down, as well as the variation of the corresponding ductility, are presented in tabular form therein and compared with mild and high strength steels. It was also recommended that the VHSS material's residual properties are sensitive to the maximum attained temperature and heating duration only for temperatures up to $650-700{ }^{\circ} \mathrm{C}$.

Alike, Heidarpour et al. (2014) highlighted the differentiation of VHSS compared to mild and high strength steel, regarding the mechanical properties at elevated temperatures. The behaviour of the modulus of elasticity was reported to be similar to the corresponding ones of mild and high strength steel. According to the literature, this is attributed to the fact that, not the particular sensitivity of the elastic modulus to the different microstructures between the steel grades is expected.

An elaborate work by Mirmomeni et al. (2015) which is combining pre-deformation, the rate of loading, and elevated temperatures is worth presenting. An interesting attempt has been made to present the aspects of real fire conditions, although it is related to mild steel. The tests for the highest strain rate $\left(10 \mathrm{~s}^{-1}\right)$ have shown $48 \%$ increase of the yield strength with subsequent $88 \%$ reduction of the ultimate strain, compared to the slowest loading case $\left(0.00033 \mathrm{~s}^{-1}\right)$ for room temperature. Furthermore, the beneficial effect on yield and ultimate strengths of the pre-damage has been highlighted, ranging from 1.5 (high temperatures) to 2.5 (low temperatures) times the corresponding strength of the material without pre-damage. Generally, the higher the attained temperatures are, the less susceptible the other parameters become, while the sensitivity due to strain rate and pre-deformation for the same temperatures was higher for the retained yield stresses.

Wang et al. (2015) investigated the Q460 grade steel, which is produced by heat treatment using quenched and tempered process, in contrary to the normalized steel S460 NL, which has been explored by Qiang et al. (2012b). Indeed, significant differences have been observed on the retained elasticity between Q460 and
S460, which emphasize the importance of the manufacturing process on the mechanical behaviour of steel after subjected to fire and cooled down. Namely, the original elastic modulus of the quenched steel has been observed after cooling down from temperatures up to $800{ }^{\circ} \mathrm{C}$, while elastic modulus of the S460 decreases to $80 \%$, respectively. Yield and ultimate strength have similar qualitative characteristics for the two steel grades. Finally, equations predicting the post-fire reduction factors for high strength Q460 steel have been proposed.

Furthermore, some visual observations have been demonstrated therein, depending on the surface colour, as they are valuable for an approximate estimation of the experienced temperature in steel. In particular, at a temperature of $300{ }^{\circ} \mathrm{C}$, blue colour has been observed (blue brittleness phenomenon), while above $600{ }^{\circ} \mathrm{C}$, the surface becomes dark and the fire damage on the steel specimens has been visible. In addition, the surface is clean for specimens cooled in air, while rust has been observed for the ones cooled by water.

The issues of residual stresses after the fire and subsequent natural cooling in welded $\mathrm{H}$-sections have been addressed by Wang and Qin (2016). The results showed that the residual stresses decreased rapidly after the member is exposed to temperatures greater than $400{ }^{\circ} \mathrm{C}$ while only $10 \%$ of the residual stresses before heating remains. This behaviour was observed both for mild steel and high strength steel sections. Furthermore, a residual stress model has been proposed for $\mathrm{H}$-sections with flange and web thicknesses around $8 \mathrm{~mm}$. The importance of the plate thickness on the magnitude of residual stress has been highlighted as well. In particular, greater residual stresses after constant welding heat have been observed for thinner plates, probably due to the smaller cross-sectional area.

The investigation of the microstructure alterations contributes to a better understanding and offers insight into the behaviour of steel during heating and cooling processes. Interesting attempts have been implemented by researchers (e.g., Cantwell et al., 2016 and Guo et al., 2015), who investigated the grain size variations through electron scanning techniques. Also, studies in steel features under fire conditions presented by Digges et al. (1966), Smith et al. (1981), Kirby et al. (1986) and Tide (1998). A useful discussion for the microstructure transformations is included in a previous work of the authors, where more details and illustrations are presented. One should have in mind, that the time-temperature-transformation diagrams, as presented by Maraveas et al. (2017), demonstrate the resulting microstructures, taking into account the critical cooling and isothermal curves for three different steel types (hypereutectoid, eutectoid, and alloy steel).

The atoms transition, from a face-centered cubic (FCC) to a body-centered cubic structure (BCC), is 
clearly illustrated in the thermal properties of high strength steel at elevated temperatures. Choi et al. (2014) confirmed the latter behaviour when they performed experimental tests at elevated temperatures in order to obtain the thermal and mechanical properties of HSA800 high-strength steel. In particular, a $60 \%$ spike of the specific heat of the material was observed between 700 and $800{ }^{\circ} \mathrm{C}$, while the thermal conductivity also changes trend at the same temperatures (Table 1). This behaviour is addressed by EN1993 (2005) and ASCE (1992) as well.

The main differences regarding the thermal properties of conventional and high-strength steel are also noted by Khaliq (2013). In general, vanadium steel displays higher specific heat than the corresponding one of mild steel. Regarding the thermal conductivity, no significant differences between the two types of steel are noticed, although the response of A36 steel is smoother. The thermal expansion of the vanadium steel as a function of temperature, records the same behaviour, compared with the corresponding one of the HSA800 results by Choi et al. (2014). Linear relationships, predicting the thermal properties of vanadium steel, as a function of temperature, have been proposed.

Focusing on VHSS, the effect of microstructure alterations of each steel type on the resulted strength has been discussed in detail by Azhari et al. (2015). In contrast to mild and high-strength steels, the kinetics of tempering during the heat treatment of VHSS (relatively fast grain growth), resulting in a quick loss of strength for VHSS. The latter is described as "poorer thermal stability of the VHSS", in comparison with mild and highstrength steels, by Heidarpour et al. (2014). In the latter study, it is noted that the austenitization and subsequent martensitization results in restoring the mechanical properties of fire-damaged VHSS. However, the austenite formulation requires that the steel exhibits very high temperatures $\left(\sim 1000{ }^{\circ} \mathrm{C}\right)$. Scanning electron microscope images of the VHSS fracture surface are well illustrated in the same study. The microstructure alterations are easily observed for seven different temperatures (up to $600{ }^{\circ} \mathrm{C}$ ), while significant differences are highlighted for temperatures above $300{ }^{\circ} \mathrm{C}$.

A noteworthy figure comparing representative microstructures for various steel grades is attached in the NIST Report (2011). For completeness, it is regenerated herein in Fig. 2. One can identify the differentiation of the morphology as the yield strength increases (250$420 \mathrm{MPa}$ ), which happens as micrographs are ordered from (a) to (h). All steels have the ferrite(white)-pearlite(gray-black) microstructures, except (i) which is a quenched and tempered steel (most possibly tempered martensite morphology) with $690 \mathrm{MPa}$ yield strength. The detailed chemical composition and further description are also included in the corresponding Technical Note, NIST (2011).

\section{Studies on members and large-scale models}

Many researchers have investigated, both experimentally and computationally, the behaviour of steel members or steel structures under fire conditions. Tondini et al. (2013), Sun et al. (2014), Song et al. (2010) and Chen and Young (2008) have focused on steel and composite members as well as steel joints under combined fire and loading conditions. Additionally, important large-scale tests were performed lately by Vassart et al. (2012) and Johnston et al. (2016). In all cases, the finite element (FE) models have been developed and compared with the corresponding experimental results. Almost every study reviewed in the current section regards either high-strength or cold-formed steel with strength greater than $460 \mathrm{MPa}$. Furthermore, an evident disagreement is observed for the predictions made by the existed standards. The last finding increases substantially the

Table 1 Summary of Test Data for HSS and VHSS at elevated temperatures

\begin{tabular}{|c|c|c|c|c|c|c|}
\hline Source & Number of specimens & Number of curves & Manufacture process & Steel type & Average $f_{y}(\mathrm{MPa})$ & $\mathrm{T}\left({ }^{\circ} \mathrm{C}\right)$ \\
\hline Holt (Unknown) & 10 & - & quenched and tempered & ASTM A514 & 816 & $27-1038$ \\
\hline USS (1972) & 10 & - & quenched and tempered & ASTM A514 & 803 & $27-1038$ \\
\hline NIST TN1714 & 10 & - & quenched and tempered & - & 760 & 20-701 \\
\hline Chen et al. (2006) & 34 & 12 & quenched and tempered & S690Q & 789 & $60-940$ \\
\hline Qiang et al. (2013a) & 26 & 12 & normalized & S460 N & 510 & $100-700$ \\
\hline Choi et al. (2014) & 10 & 10 & quenched and tempered & HSA 800 & 701 & $100-900$ \\
\hline Wang et al. (2013) & 22 & 11 & alloy steel & Q460 & 503 & $100-800$ \\
\hline Heidarpour et al. (2014) & 14 & 14 & quenched and tempered & VHS & 1307 & $50-600$ \\
\hline Chiew et al. (2014) & 10 & 10 & reheated, quenched and tempered & RQT-S690 & 773 & $100-800$ \\
\hline Xiong and Liew (2016) & 18 & 17 & quenched and tempered & RQT 701 & 740 & $100-800$ \\
\hline Lazić et al. (2016) & 22 & 10 & quenched and tempered & S690QL & 775 & $250-550$ \\
\hline Qiang et al. (2016) & 24 & 24 & quenched and tempered & S960QL & 1045 & $100-700$ \\
\hline
\end{tabular}




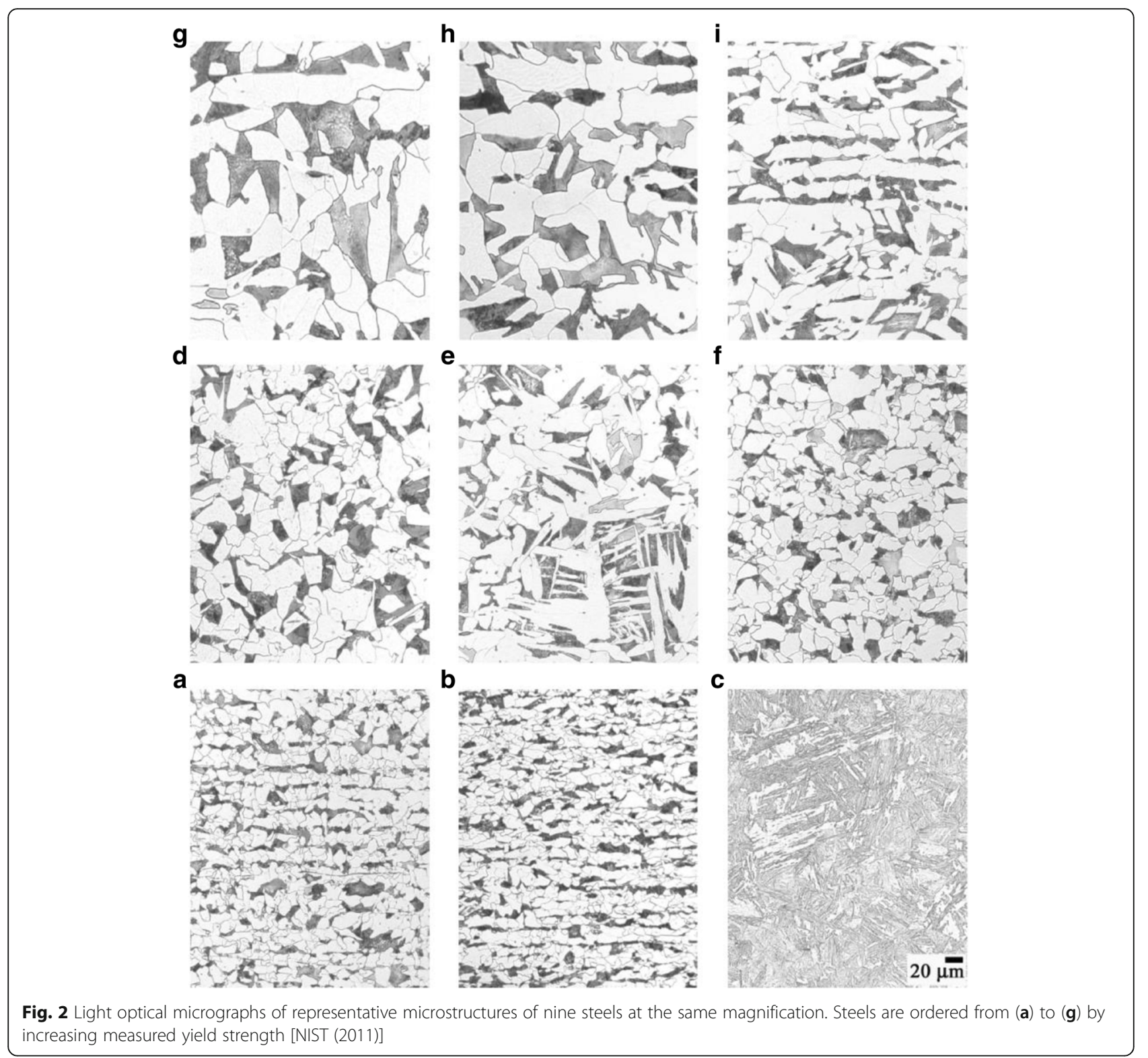

possibility of making the fire, a critical loading condition during the design of structures made of high and very high strength steels.

Wang's (2004) study has significantly contributed towards the direction of the post-buckling behaviour of axially restrained and loaded steel columns under fire conditions. A translational spring was introduced in the direction of the member, along with the loading conditions (i.e., initial axial load and increasing temperature). A parametric investigation followed for two crosssections, combining the initial column load magnitude, the restraint stiffness, and the unloading restraint stiffness. Results have indicated that the post-buckling contribution is significant, mostly for slender columns with low initial load and high restraint stiffness (over 5\% of the column axial stiffness). A simplified analytical method has been proposed therein, the reliability of which has been also illustrated.

Several parameters have been investigated by Naser and Kodur (2016) for the resultant failure capacity of steel beams at fire conditions. An interesting observation regards local web instabilities, which were found to be of primary importance since they take place before flexural failure. On the other hand, there is a significant difference on the deflection curve, taking into account the concrete slab participation.

The significance of using accurate mechanical properties at elevated temperatures is also highlighted by Ranawaka and Mahendran (2010). The influence of the residual stresses on the ultimate failure load, for the case 
of distortional buckling, has been found to be small (less than 1\%). For the simulation of the residual stresses at elevated temperatures, a linear reduction relationship, proposed by Lee (2004), has been adopted.

Choe et al. (2016) compared detailed test data of temperature and axial load histories (including highstrength steel specimens with yield stress up to $520 \mathrm{MPa}$ for the virgin material) with the corresponding stressstrain models proposed by the NIST and Eurocode 3. The results indicated that the Eurocode is more conservative on predicting the buckling behaviour since its retained elastic moduli at elevated temperatures are smaller than those of the NIST model. Moreover, updates have been proposed for AISC specifications, by replacing the yield strength and modulus of elasticity retention factors based on the NIST stress-strain model.

Heva and Mahendran (2008) have highlighted the need for new design guidelines predicting the behaviour of cold-formed steel at elevated temperatures since hitherto the capacity has been determined according to the ambient temperature guidelines using the corresponding reduced mechanical properties. This is not a formalised design procedure, taking into account that cold-formed members behave differently than the hot-rolled steel members. Indeed, this approximate approach appears to be conservative for unstiffened sections, according to the experimental investigation that has been followed by Heva and Mahendran. As a result, the critical limit of $350{ }^{\circ} \mathrm{C}$ recommended by the Eurocode (EC3-Part 1.2), while using the effective width with the corresponding retained mechanical properties at ambient temperatures, contribute to completely uneconomical design.

Another important large-scale test has been performed by Johnston et al. (2016). The failure through in-plane, inward collapse mechanism has been clearly provided by the side rails and the cladding, herein, while the asymmetric mode is attributed to the non-uniform loading condition of the fire. The columns buckled at a distance offset from the joints while the screwed joints have not failed. In addition, the effect of joint stiffness on the collapse temperature has been studied through FE analyses. The lack of any guidance for the design of cold-formed steel portal frame structures in fire boundary conditions has also been noted.

It is worth to mention, that current codes should take into account the behaviour of the structure, along with a realistic material model prediction. A motivating work towards this direction has been published recently by Maraveas et al. (2017), describing the major aspects of the post-fire assessment and reinstatement of steel structures.

\section{Mechanical properties of HSS at elevated temperatures}

The above studies mainly focused on the mechanical properties of steel since many tests have been conducted on high-strength steel coupons after heating and cooling treatment. The present work is a comprehensive insight of the extensive literature review. Numerous test data are compared following accurate classification; while the retained mechanical properties are presented and the post-fire mechanical properties are examined separately. For every case, efficient proposed equations found in the literature are presented.

\section{Experimental results}

The details of the considered tests for coupons heated to specific temperatures (i.e., numbers of specimens and stress-strain curves, manufacturing, and steel type information and temperature range), are summarized in Table 1. Subsequently, all the available test data are illustrated in Fig. 3, for the case of yield stress (a), ultimate stress (b) and modulus of elasticity (c). Where $f_{y}, f_{u}$ and $E_{S}$ are the reference yield strength, ultimate strength and elastic modulus, respectively (i.e., before the fire exposure), while those with the subscript $\mathrm{T}$ are the corresponding temperature dependent values. For comparative reasons, some predictive models of existing codes are also illustrated. The investigation of the stress-strain curves exceeds the limits of the present study. As an important aspect of the design, the necessity for future work emerges for the development of a generic stress-strain model for high-strength steel. However, a representative drop of the curves with increasing temperature can be observed in Fig. 4, through the elaborate experimental works by Qiang et al. (2016) and (2013b), for S690 structural steel at elevated temperatures and after cooling down (Figs. 4a and $b$, respectively).

Initially, one can easily notice that a substantial deterioration of all mechanical properties is demonstrated for temperatures above $500{ }^{\circ} \mathrm{C}$, while the variance of the results is significant too. Also, the grade of high-strength steel (460 or $690 \mathrm{MPa}$ ) cannot be considered as a key aspect for distinction purposes.

The data for the yield and ultimate stresses of very high-strength steel (Fig. 3a and b) were collected from two studies. The results of the work by Heidarpour et al. (2014) are particularly deteriorated (triangle marker style); thus, they are distinguished and investigated separately from the ones resulted by Qiang et al. (2016). The latter observation cannot be attributed to the loading procedure, since the same strain rates have been implemented for the corresponding steady-state tests conducted on S960 by Qiang et al. (2016), namely $0.005 \mathrm{~min}^{-1}$. The importance of the strain rate on the strength results has been highlighted in the previous section. It is rather attributed to the fact that, as observed in the microstructure pictures, above $350{ }^{\circ} \mathrm{C}$, "the carbide particles continue to coarsen" leading to lower thermal stability, which further deteriorates the strength properties. In any case, 


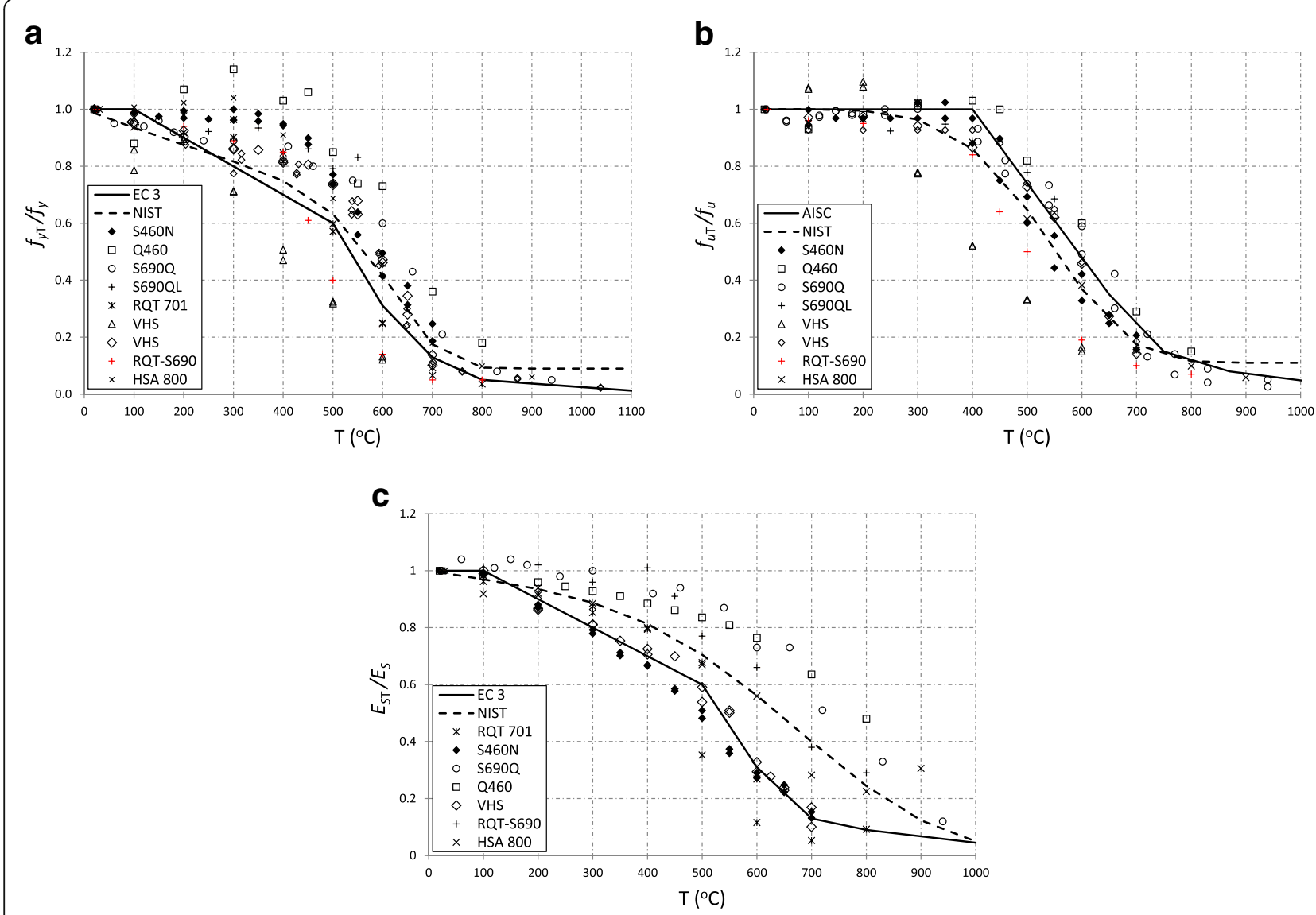

Fig. 3 Reduced ratios of a) $f_{y T} / f_{y^{\prime}}$ b) $f_{u T} / f_{u}$ and $\left.\mathbf{c}\right) E_{s T} / E_{s}$ at elevated temperatures
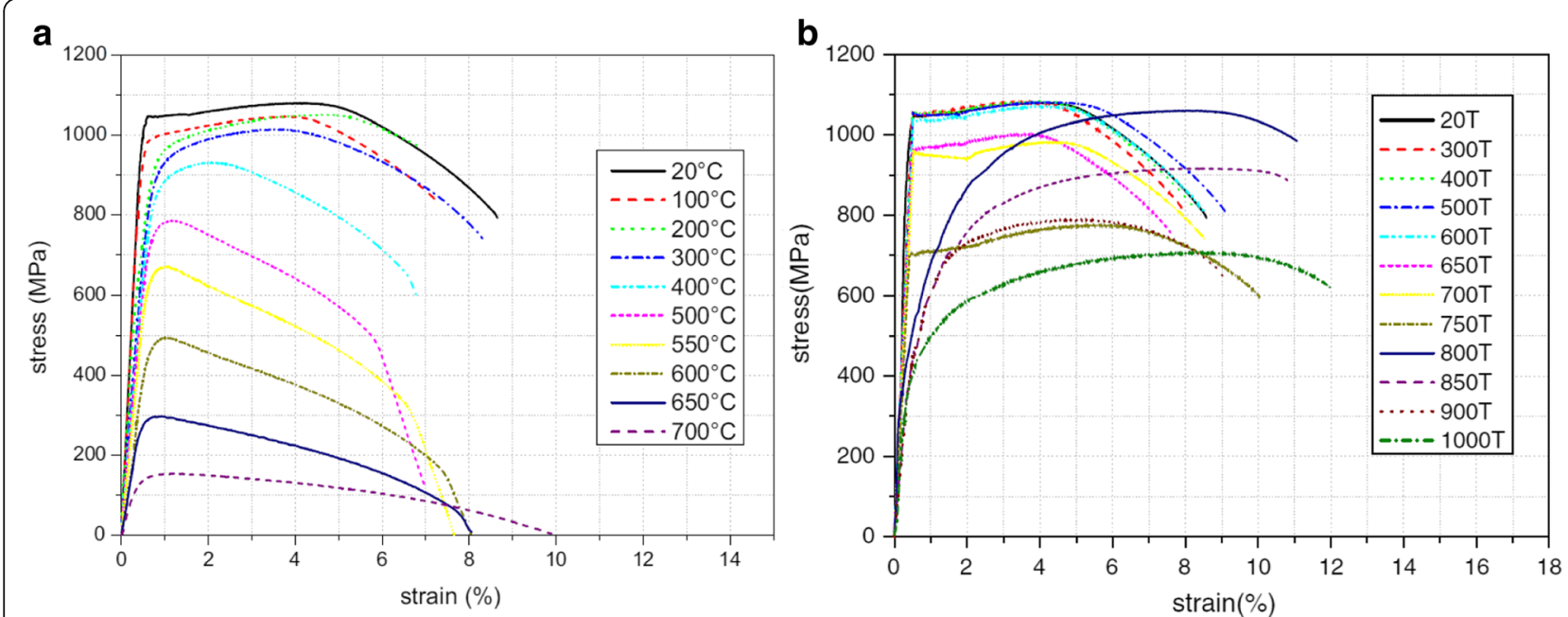

Fig. 4 Representative stress-strain curves for $\mathrm{S} 690$ high strength steel a) at elevated temperatures and $\mathbf{b}$ ) after cooling down [Qiang et al. (2016) and (2013b)] 
very high strength steel at elevated temperatures is recommended for further experimental investigation.

Furthermore, in Fig. 3c, the retained elastic modulus can be easily clustered in two groups. The group with lower degradation regards the steels Q460 (by Wang et al., 2005) and S690Q (by Chen et al., 2008). The elastic modulus in the first study was obtained from steady-state tests (through the frequency approach) and in the second one from both steady-state and transient tests. It is also reported by Chen et al. (2008) that the elastic modulus calculated by the steady-state tests exhibited lower reduction than those from the transient tests. However, although the first ones are not included in the study in a tabulated form, the reduction between the two cases is more than obvious in the graphical form. From the authors' point view, more experimental data for the retained elastic modulus of high-strength steel are required before drawing a safe reduction model in the form of design guidelines.

\section{Comparison with existing codes}

As it is already known, all predictive models for the behaviour of steel at elevated temperatures suggested by the current codes, are based on mild steel test coupons, except the NIST report, which includes specimens with yield stress up to $500 \mathrm{MPa}$. Thus, the disagreement of the existing guidelines with the test results is simply confirmed, rather than expected. It should be noted that since almost every collected yield strength data implies the $0.2 \%$-offset yield strength, the corresponding curves are referred to the same material property. In addition, the most recent report of the NIST TN 1907 (2016) is taken into account for the comparison of the corresponding material models.

Although some existing codes have been reported conservative even for mild steel, this is not the case when they are used for high strength steel. In Fig. 3a, one can observe the overestimation of the NIST at $700{ }^{\circ} \mathrm{C}$ for the yield stress while Eurocode 3 is significantly conservative for temperatures between 350 and $600{ }^{\circ} \mathrm{C}$ (Fig. 3c). Similar observations apply to the American organizations (i.e. AISC and ASCE). As mentioned previously, some researchers have already highlighted the inconsistencies of several guidelines with the experimental results [Chen et al. (2006), Heva and Mahendran (2008), Qiang et al. (2016), etc.].

\section{Proposed model}

A simplified proposed model, predicting the mechanical properties of high-strength steel at elevated temperatures, is depicted in Fig. 5.
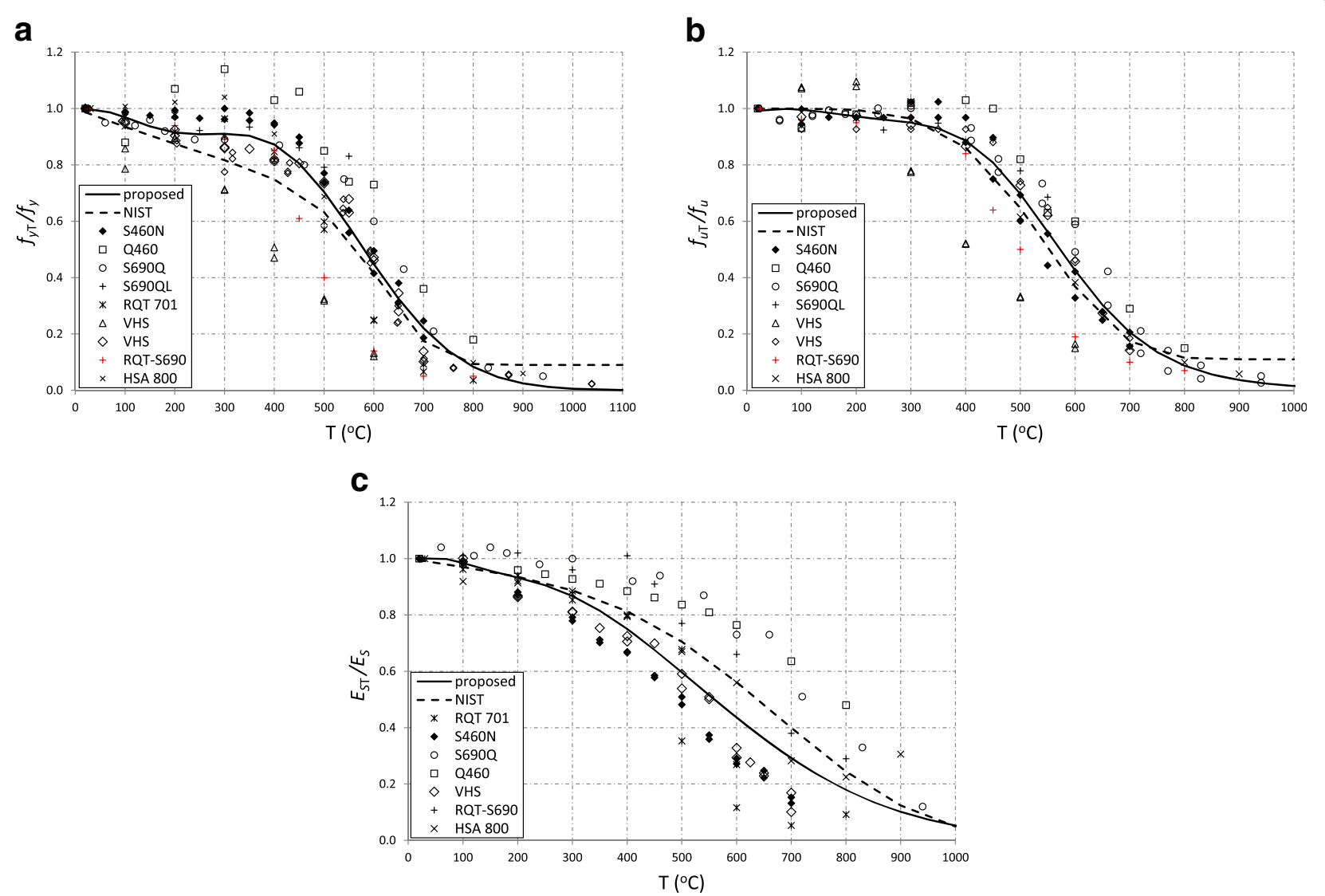

Fig. 5 Material properties reduction fit \& comparison with the NIST (2016), for a yield strength, b ultimate strength and c elastic modulus 
The proposed nonlinear model is based on the test data presented in section 3.1, which are also illustrated in the same figures. The reduction factors for each mechanical property (i.e. proportional yield strength, ultimate strength, and elastic modulus) are determined via Eqs. (1-2), for $\mathrm{i}=(\mathrm{y}, \mathrm{u}, \mathrm{E})$. Specifically, two alternative formulas are proposed, namely using exponential and summation of sines forms respectively. To this end, a nonlinear fitting method was followed using Matlab. The estimated R-square for the yield and ultimate strengths and the elastic modulus fitting analyses were observed around 0.88 (1.7), 0.91 (1.2) and 0.79 (1.9) respectively. Towards a better understanding, R-square with a value closer to 1 indicates that a greater proportion of variance is accounted for by the model. The sum of squares due to error (SSE) are also given for each property in the brackets. The parameters a, b and c are summarized in Tables 2 and 3 for the determination of the reduced mechanical properties at elevated temperatures. The efficiency of the proposed formulas should be highlighted since the user is able to calculate the retained properties for the entire range of temperatures by a single formula.

$$
\begin{aligned}
& k_{(i=y, u, E)}=\mathrm{a}_{i, 1} e^{-\left(\frac{x-b_{i, 1}}{c_{i, 1}}\right)^{2}}+\mathrm{a}_{i, 2} e^{-\left(\frac{x-b_{i, 2}}{c_{i, 2}}\right)^{2}} \\
& k_{(i=y, u, E)}=\mathrm{a}_{i, 1} e\left(b_{i, 1} x+c_{i, 1}\right)+\mathrm{a}_{i, 2} \sin \left(b_{i, 2} x+c_{i, 2}\right)
\end{aligned}
$$

The predictability of the proposed model using Eq. (1), can be easily observed through the residuals plot (namely the deviations of the literature data from the fitted retained properties), in Fig. 6. Mathematically, the residual for a specific predictor value is the difference between the response value $\mathrm{R}$ and the predicted response value $\hat{R}$. For a better understanding of the regression, a 5-order polynomial trend line (solid curve) is added in every figure. It is obvious that the best accuracy is observed for the ultimate strength, where the trend line approaches zero at the greatest extent of the temperatures range.

In Fig. 7, one can observe the formula differentiations between Eqs. (1) and (2). For the formula based on the

Table 2 Parameters for Eq. (1) of the proposed model

\begin{tabular}{llll}
\hline parameter & $k_{y}$ & $k_{u}$ & $k_{E}$ \\
\hline $\mathrm{a}_{1}$ & -85.81 & 0.9878 & 0.1871 \\
$\mathrm{~b}_{1}$ & 184.4 & 40.68 & -12.96 \\
$\mathrm{c}_{1}$ & 297.7 & 469.1 & 132 \\
$\mathrm{a}_{2}$ & 86.73 & 0.3482 & 0.9199 \\
$\mathrm{~b}_{2}$ & 184.2 & 437.9 & 181.6 \\
$\mathrm{c}_{2}$ & 299.8 & 205.9 & 483.9 \\
\hline
\end{tabular}

Table 3 Parameters for Eq. (2) of the alternative proposed model

\begin{tabular}{llll}
\hline parameter & $k_{y}$ & $k_{u}$ & $k_{E}$ \\
\hline$a_{1}$ & 7.565 & 4.193 & 2.542 \\
$b_{1}$ & 0.0001617 & 0.000294 & 0.000287 \\
$c_{1}$ & 2.984 & 2.853 & 2.771 \\
$a_{2}$ & 0.1442 & 0.1515 & 0.1714 \\
$b_{2}$ & 0.008655 & 0.008375 & 0.005308 \\
$c_{2}$ & -1.958 & -1.673 & 0.3929 \\
\hline
\end{tabular}

summation of sines (dashed lines), a sudden drop is observed for temperatures up to $100{ }^{\circ} \mathrm{C}$, for the cases of yield strength and elastic modulus. According to the authors' point of view, an ideal case is the calculation through Eq. (1) (Gaussian fit). However, it is left to the user to make a decision.

\section{Post-fire properties of HSS}

The details of the tests that have been conducted on coupons after heating and subsequent cooling at ambient temperature are summarized in Table 4. The cooling method is also included, whereas the heating was performed through furnaces.

The available test data are illustrated in Fig. 8(a-c). The predictive factors are also presented in the same figures for each mechanical property, as they have been proposed by Maraveas et al. (2017). For the case of postfire material properties, a simple tri-linear model is proposed. It is important to note that, although Eqs. (3)-(5) have been established for heat-treated steel, in general, they are in agreement with the test results for high-strength steel. Therefore, the predictive Eqs. (3)-(5) can be used for the post-fire properties of high-strength steel as well, i.e. the yield and ultimate stresses and elastic modulus respectively.

For the case of post-fire retained elastic modulus, one can observe the deviations between the experimental data in Fig. 8c. More specifically, for temperatures above $700{ }^{\circ} \mathrm{C}$, some experimental results (red-coloured) are obtained almost to retain their initial elastic modulus. These data correspond to Q460 and RQT-S690 structural steels. Regarding the first steel, the specimens were cooled in water, so the insignificant reduction of the property is expected because of the quenching and tempering procedures. On the contrary, the specimens cooled in a furnace (S355)2H steel) are characterized by large dispersion, while significant reduction is observed in medium temperatures $\left(500-600{ }^{\circ} \mathrm{C}\right)$. As for the reheated, quenched and tempered steel (RQT-S690), an important discussion is followed by Chiew et al. (2014) comparing their findings with the corresponding ones for S690QL steel, published by Qiang et al. (2012a). In addition, from the investigation at elevated temperatures followed in the same study, the elastic modulus 

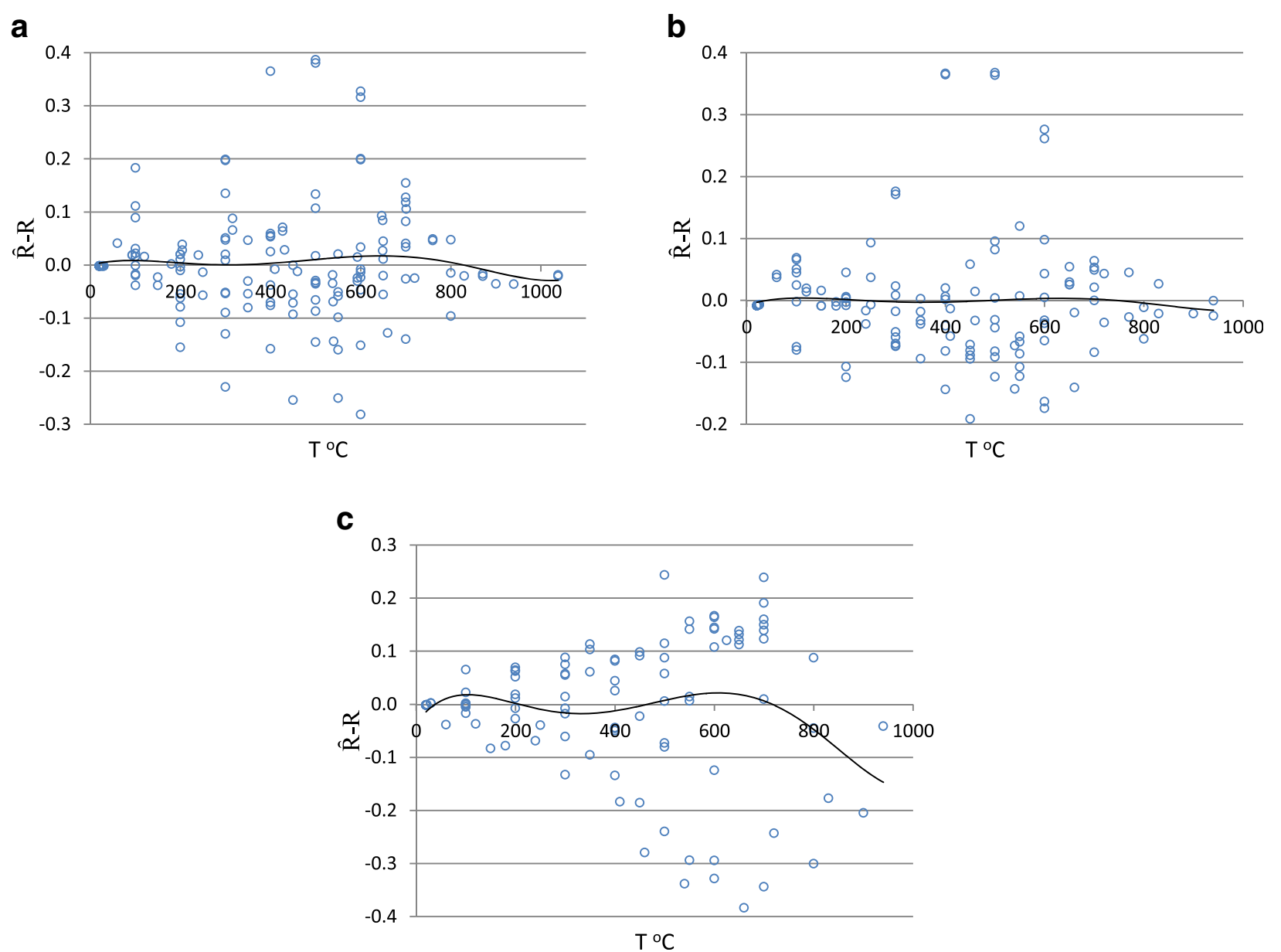

Fig. 6 Residuals of material properties after the fitting analysis, for a) yield strength, b) ultimate strength and $\mathbf{c}$ ) elastic modulus

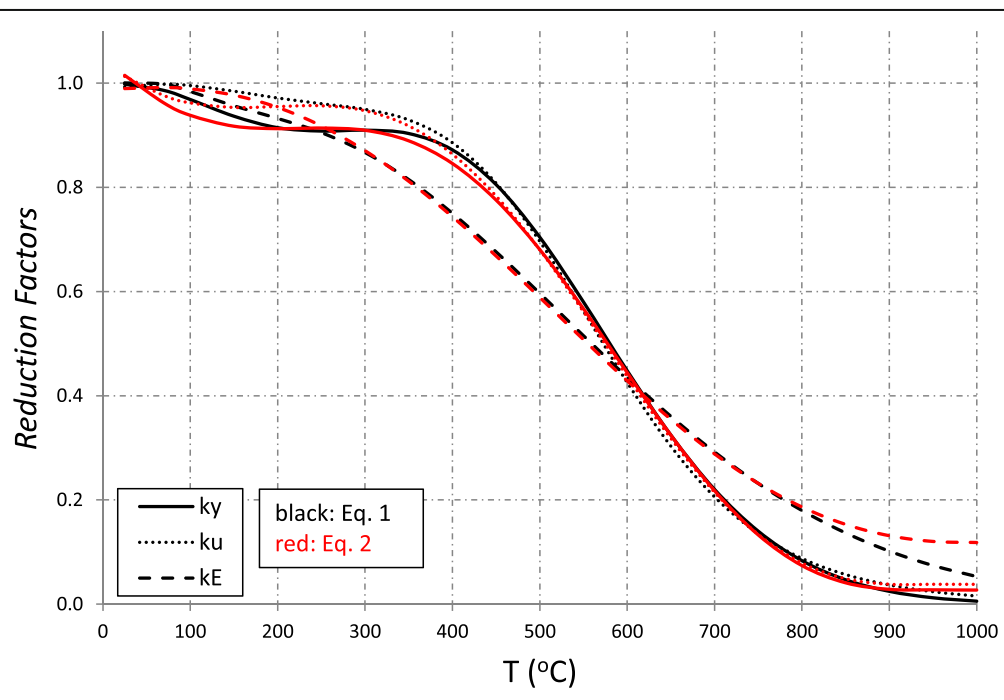

Fig. 7 Comparison of the reduction curves for Eqs. (1)-(2) 
Table 4 Summary of Test Data for HSS and VHSS after heated and cooled down

\begin{tabular}{|c|c|c|c|c|c|c|c|}
\hline Source & $\begin{array}{l}\text { Number of } \\
\text { specimens }\end{array}$ & $\begin{array}{l}\text { Number of } \\
\text { curves }\end{array}$ & Manufacture process & Steel type & $\begin{array}{l}\text { Average } f_{y} \\
(\mathrm{MPa})\end{array}$ & $\mathrm{T}\left({ }^{\circ} \mathrm{C}\right)$ & $\begin{array}{l}\text { Cooling } \\
\text { method }\end{array}$ \\
\hline $\begin{array}{l}\text { Outinen and Mäkeläinen } \\
\text { (2004) }\end{array}$ & 14 & - & Cold worked & $\mathrm{S} 355 \mathrm{~J} 2 \mathrm{H}$ & 566 & $464-538$ & $\mathrm{CIF}^{\mathrm{a}}$ \\
\hline \multirow[t]{2}{*}{ Qiang et al. (2012b) } & 11 & 11 & Hot rolled & $S 460$ & 490 & $\begin{array}{l}300- \\
1000\end{array}$ & $\mathrm{CIA}^{\mathrm{b}}$ \\
\hline & 13 & 13 & Heat treated & S690 & 789 & $\begin{array}{l}100- \\
1000\end{array}$ & $\mathrm{CIA}$ \\
\hline Qiang et al. (2013) & 11 & 11 & Heat treated & S960 & 1045 & $\begin{array}{l}100- \\
1000\end{array}$ & $\mathrm{CIA}$ \\
\hline Chiew et al. (2014) & 6 & 6 & $\begin{array}{l}\text { quenched and } \\
\text { tempered }\end{array}$ & RQT-S690 & 773 & $\begin{array}{l}100- \\
1000\end{array}$ & $\mathrm{CIA}$ \\
\hline $\begin{array}{l}\text { Gunalan and Mahendran } \\
\text { (2014) }\end{array}$ & 30 & 30 & Cold-formed & G500, G550 & 664 & $300-800$ & $\mathrm{CIA}$ \\
\hline Wang et al. (2014) & 20 & 20 & Stainless & $\begin{array}{l}\text { Grade } \\
1.4301\end{array}$ & 623 & $\begin{array}{l}200- \\
1000\end{array}$ & $\mathrm{CIF}$ \\
\hline Wang et al. (2015) & 48 & 48 & $\begin{array}{l}\text { quenched and } \\
\text { tempered }\end{array}$ & Q460 & 513 & 300-900 & $\mathrm{CIA}, \mathrm{CI} \mathrm{W}^{\mathrm{C}}$ \\
\hline Azhari et al. (2015) & 12 & 12 & $\begin{array}{l}\text { quenched and } \\
\text { tempered }\end{array}$ & VHS & 1200 & $150-600$ & $\mathrm{ClA}$ \\
\hline
\end{tabular}

${ }^{\mathrm{a}}$ cooling in furnace; ${ }^{\mathrm{b}}$ cooling in air; ${ }^{\mathrm{c}}$ cooling in water
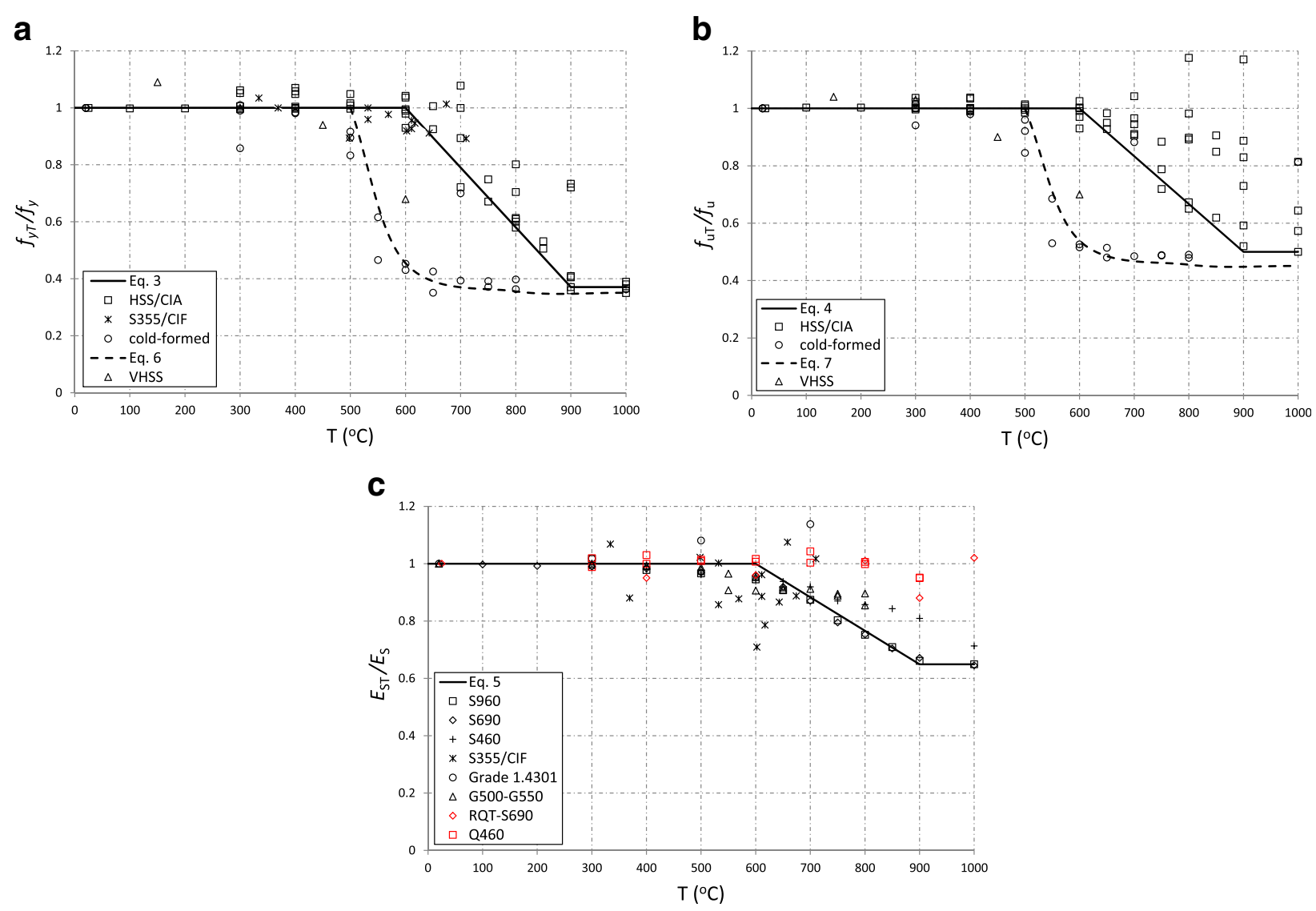

Fig. 8 Reduced post-fire ratios of a) $\left.f_{y T} / f_{y}, \mathbf{b}\right) f_{u T} / f_{u}$ and $\left.\mathbf{c}\right) E_{S T} / E_{S}$ as a function of temperature 
was attained poorer deterioration, compared to other materials referenced therein, while the strengths were drastically reduced. From the aforementioned, it is clear that the refined quenched and tempered product is another special case of high-strength steel, which should be taken into consideration in particular, with the aid of more experimental data.

The case of cold-form steel has been investigated separately since the behaviour is evidently different in terms of yield and ultimate strength. Specifically, the corresponding strengths are reduced by half in the range 500 and $600{ }^{\circ} \mathrm{C}$. Similarly, post-fire mechanical properties for VHSS can be predicted according to the latter case; namely, by using Eq. (5) for the elastic modulus and Eqs. (6)-(7) for the yield and ultimate stresses respectively.

The rapid strength reduction of the cold-form steel is undoubtedly attributed to the different manufacturing process. In the microstructure level, the strength enhancing martensite phase, which is gained from large plastic deformation and high strain rate at low temperatures (cold-forming), obviously reverts to the lower strength austenitic phase. This phenomenon could be linked to the corresponding "return back" of the heat treated steels into their "parent" steel before hardening if heated properly.

Residual factors of heat-treated steel:

$$
\begin{aligned}
& \frac{f_{y T}}{f_{y}}= \begin{cases}1 & T \leq 600^{\circ} C \\
2.258-T / 480, & 600^{\circ} C<T<900^{\circ} C \\
0.371 & T \geq 900^{\circ} C\end{cases} \\
& \frac{f_{u T}}{f_{u}}= \begin{cases}1 & T \leq 600^{\circ} C \\
2.0-T / 600, & 600^{\circ} C<T<900^{\circ} C \\
0.500 & T \geq 900^{\circ} C\end{cases} \\
& \frac{E_{s T}}{E_{s}}= \begin{cases}1 & T \leq 600^{\circ} C \\
1.702-T / 85, & 600^{\circ} C<T<900^{\circ} C \\
0.649 & T \geq 900^{\circ} C\end{cases}
\end{aligned}
$$

Residual factors of cold-worked steel:

$$
\begin{array}{cc}
\frac{f_{y T}}{f_{y}}=\left\{\begin{array}{lc}
1 & T \leq 500^{\circ} \mathrm{C} \\
0.65 \cdot(500 / T)^{10}+0.35, & T>500^{\circ} \mathrm{C}
\end{array}\right. \\
\frac{f_{u T}=1}{f_{u}}=\begin{array}{lc}
1 & T \leq 500^{\circ} \mathrm{C} \\
0.55 \cdot(500 / T)^{10}+0.45, & T>500^{\circ} \mathrm{C}
\end{array}
\end{array}
$$

\section{Conclusions}

This study addresses the mechanical properties of highstrength steel at elevated temperatures and after cooling to ambient temperature. An attempt to understand the behaviour of HSS and VHSS, as well as their disparity against mild steel, at elevated temperature is firstly presented. A thorough review is followed, presenting the findings of experimental tests conducted on HSS and VHSS coupons or column members and large-scale frames at fire conditions. Major parameters, such as the microstructure particularity and the manufacturing process are highlighted.

Given that the grade of high-strength steel is used for high strength-to-weight ratio demands, thinner structural elements are used for the optimal weight of the structure. Thus, the greater section factor results in a more critical design capacity. Additionally, as illustrated in this study, high-strength steels exhibit more unstable conditions during heating than that of conventional steel. These facts imply the case of fire design as a crucial loading condition when using high-strength steel.

Mechanical properties from the experimental tests are summarized and presented in graphical forms. The disagreement of the available results with the existing codes of practice implies the necessity of the appropriate updates. Therefore, a sophisticated but simple-to-use nonlinear model is proposed for predicting the retained strength factors for high-strength steel at elevated temperatures.

In addition, post-fire properties of HSS and VHSS are examined in this paper. A tri-linear formula is found adequate for this scenario and an exponential one for the cold-formed steel. The results indicate good agreement with the proposed equations earlier presented by the authors (Maraveas et al., 2017). At last, it is suggested that the fire and the post-fire elastic modulus of HSS need further experimental investigation.

\section{Abbreviations \\ $T$ : Is the attained temperature; $f_{\mathrm{y}}$ : Is the yield stress of steel at ambient temperature; $f_{u}$ : Is the ultimate stress of steel at ambient temperature; $E_{s}$ : Is the elastic modulus of steel at ambient temperature; $f_{y T}$ : Is the yield stress of steel at elevated temperature; $f_{u T}$ : Is the ultimate stress of steel at elevated temperature; $E_{S T}$. Is the elastic modulus of steel at elevated temperature}

\section{Acknowledgments}

This research was supported by the University of Liege and the EU in the context of the FP7-PEOPLE-COFUND-BeIPD project.

Author's contributions

All authors equally contributed in this work. All authors read and approved the final manuscript.

\section{Competing interests}

The authors declare that they have no competing interests.

\section{Publisher's Note}

Springer Nature remains neutral with regard to jurisdictional claims in published maps and institutional affiliations.

\section{Author details}

${ }^{1}$ University of Liege, Liege, Belgium. ${ }^{2}$ National Technical University of Athens, Athens, Greece. ${ }^{3}$ University of Leeds, Leeds, UK. 
Received: 30 November 2016 Accepted: 17 July 2017 Published online: 27 July 2017

\section{References}

AISC (American Institute of Steel Construction) (2010) Specification for structural steel buildings. American institution of steel construction, Chicago, USA

AS (Australian Standard) (2012) AS 4100-A1: Amendment no. 1 to AS 4100-1998 steel structures. Sydney: Australian Building Codes Board (ABCB)

ASCE (American Society of Civil Engineers) (1992) Structural fire protection. American Society of Civil Engineers, New York, USA

Azhari F, Heidarpour A, Zhao XL, Hutchinson CR (2015) Mechanical properties of ultra-high strength (grade 1200) steel tubes under cooling phase of a fire: an experimental investigation. Constr Build Mater 93:841-850

Bjorhovde R (2010) Performance and design issues for high strength steel in structures. Adv Struct Eng 13(3):403-411

BS (British Standard) (1998) BS 5950-8: structural use of steelwork in building. In: Part 8: code of practice for fire resistant design. British Institution, London, UK

Cantwell PR, Ma S, Bojarski SA et al (2016) Expanding time-temperaturetransformation (TTT) diagrams to interfaces: a new approach for grain boundary engineering. Acta Mater 106:78-86

Chen J, Young B (2008) Design of high strength steel columns at elevated temperatures. J Constr Steel Res 64:689-703

Chen J, Young B, Uy B (2006) Behavior of high strength structural steel at elevated temperatures. J Struct Eng 132(12):1948-1954

Chiew SP, Zhao MS, Lee CK (2014) Mechanical properties of heat-treated high strength steel under fire/post-fire conditions. J Constr Steel Res 98:12-19

Choe L, Zhang C, Luecke WE et al (2016) Influence of material models on predicting the fire behavior of steel columns. Fire Technol. doi:10.1007/ s10694-016-0568-4

Choi I-R, Chung K-S, Kim D-H (2014) Thermal and mechanical properties of highstrength structural steel HSA800 at elevated temperatures. Mater Des 63:544-551

Digges Th, Rosenberg S and Geil Gl (1966) Heat treatment and properties of iron and steel. National Bureau of standards, monograph 88, USA

EN 1993-1-2 (2005) 'Eurocode 3: design of steel structures - part 1-2: general rules — structural fire design'. Brussels: European Committee for Standardisation.

EN 1993-1-12 (2007) : 'Eurocode 3. In: Design of steel structures - part 1-12: additional rules for the extension of EN 1993 up to steel grades $S$ 700'. Brussels: European Committee for Standardisation.

Gunalan S, Mahendran M (2014) Experimental investigation of post-fire mechanical properties of cold-formed steels. Thin-Walled Struct 84:241-254

Guo W, Crowther D, Francis JA, Thompson A, Liu Z, Li L (2015) Microstructure and mechanical properties of laser welded $S 960$ high strength steel. Mater Des 85:534-548

Heidarpour A, Tofts NS, Korayem AH, Zhao XL, Hutchinson CR (2014) Mechanical properties of very high strength steel at elevated temperatures. Fire Saf J 64:27-35

Heva YB, Mahendran M (2008) Local buckling tests of cold-formed steel compression members at elevated temperatures. In: Proceedings of fifth international conference on thin-walled structures, Brisbane, Australia

Holt JM. Short-time elevated-temperature tensile properties of USS "T-1" and USS "T-1" type A constructional alloy steels. Progress Report 57.19-901(3)(a)-AS-EA-2, Applied Research Laboratory, United States Steel Corporation, Monroeville, Pa, unk

Johnston RPD, Lim JBP, Lau HH et al (2016) Finite-element investigation of coldformed steel portal frames in fire. ICE Proc Struct Buildings 169(SB1):3-19

Khaliq W (2013) High temperature thermal properties of vanadium steel. In: Proceedings of international conference of design, fabrication and economy of metal structures, Miskolc, Hungary, pp 377-382

Kirby BR, Lapwood DG, Thompson G (1986) The reinstatement of fire damaged steel and iron framed structures. British Steel Corporation, Swindon Laboratories, UK

Lazić V, Arsić D, Aleksandrović S et al (2016) The influence of temperature on mechanical properties of the base material (BM) and welded joint (WJ) made of steel S690QL. Meta 55(2):213-216

Lee J (2004) Local buckling behaviour and design of cold-formed steel compression members at elevated temperatures. PhD Thesis. Queensland University of Technology Brisbane, Australia

Maraveas C, Fasoulakis Z and Tsavdaridis KD (2017) Post-fire assessment and reinstatement of steelstructures. J Struct Fire Eng 8(2):181-201

Mirmomeni M, Heidarpour A, Zhao XL, Hutchinson CR, Packer JA, Wu C (2015) Mechanical properties of partially damaged structural steel induced by high strain rate loading at elevated temperatures - an experimental investigation. Int J Impact Eng 76:178-188
Naser MZ, Kodur VKR (2016) Factors governing onset of local instabilities in fire exposed steel beams. Thin-Walled Struct 98:48-57

NIST (National Institute of Standards and Technology) (2011) High-temperature tensile constitutive data and models for structural steels in fire. In: NIST technical note 1714. National Institute of Standards and Technology, USA

NIST (National Institute of Standards and Technology) (2016) Temperaturedependent material modeling for structural steels: formulation and application. In: Technical note 1907. National Institute of Standards and Technology, USA

Outinen J (2007) Mechanical properties of structural steel at elevated temperatures and after cooling down. In: Proceedings of 10th international conference on fire and materials, San Francisco, USA

Outinen J, Mäkeläinen P (2004) Mechanical properties of structural steel at elevated temperatures and after cooling down. Fire Mater J 28:237-251

Qiang X, Bijlaard F, Kolstein H (2012a) Dependence of mechanical properties of high strength steel S690 on elevated temperatures. Constr Build Mater 30:73-79

Qiang X, Bijlaard FSK, Kolstein H (2012b) Post-fire mechanical properties of high strength structural steels $\mathbf{S 4 6 0}$ and S690. Eng Struct 35:1-10

Qiang X, Bijlaard FSK, Kolstein H (2013a) Elevated-temperature mechanical properties of high strength structural steel S460N: experimental study and recommendations for fire-resistance design. Fire Saf J 55:15-21

Qiang X, Bijlaard FSK, Kolstein H (2013b) Post-fire performance of very high strength structural steel S960. J Constr Steel Res 80:235-242

Qiang X, Jiang X, Bijlaard FSK, Kolstein H (2016) Mechanical properties and design recommendations of very high strength steel S960 in fire. Eng Struct 112:60-70

Ranawaka T, Mahendran M (2010) Numerical modelling of light gauge coldformed steel compression members subjected to distortional buckling at elevated temperatures. Thin-Walled Struct 48:334-344

RJM P (2011) Fatigue strength of welded connections made of very high strength cast and rolled steels. PhD Thesis. Delft University of Technology, Holland

Schröter F (2003) Höherfeste Stähle für den Stahlbau - Auswahl und Anwendung. (in German) high-strength steels for steel structures - selection and application. Bauingenieur 78(9):426-432

Schröter F (2006) Trends of using high-strength steel for heavy steel structures. Dillinger Hüttenwerke, Germany

Smith Cl, Kirby BR, Lapwood DG, Cole KJ, Cunningham AP, Preston RR (1981) The reinstatement of fire damaged steel framed structures. Fire Saf J 4(1):21-62

Song T-Y, Han L-H, Yu B (2010) Performance of CFST column to steel beam joints subjected to simulated fire including the cooling phase. J Constr Steel Res 66:591-604

Sun Q, Guan C, Wang D (2014) Study on mechanical characteristics and safety evaluation method of steel frame structure after fire. Theor Appl Mech Lett 4(034006). doi:10.1063/2.1403406

Tide RHR (1998) Integrity of structural steel after exposure to fire. Eng J 35(1):26-38

Tondini N, Hoang VL, Demonceau J-F, Franssen J-M (2013) Experimental and numerical investigation of high-strength steel circular columns subjected to fire. J Constr Steel Res 80:57-81

USS (1972). Steels for elevated temperature service. Technical report, United State Steel Corporation

Vassart O, Bailey CG, Hawes M et al (2012) Large-scale fire test of unprotected cellular beam acting in membrane action. ICE Proc Struct Buildings 165(SB7):327-334

Wang YC (2004) Postbuckling behavior of axially restrained and axially loaded steel columns under fire conditions. J Struct Eng ASCE 130(3):371-380

Wang W, Qin S (2016) Experimental investigation of residual stresses in thinwalled welded H-sections after fire exposure. Thin-Walled Struct 101:109-119

Wang W, Liu B, Kodur V (2013) Effect of temperature on strength and elastic modulus of high-strength steel. J Mater Civ Eng ASCE 25(2):174-182

Wang XQ, Tao Z, Song TY, Han LH (2014) Stress-strain model of austenitic stainless steel after exposure to elevated temperatures. J Constr Steel Res 99:129-139

Wang W, Liu T, Liu J (2015) Experimental study on post-fire mechanical properties of high-strength Q460 steel. J Constr Steel Res 114:100-109

Xiong M-X, Liew RJY (2016) Mechanical properties of heat-treated high tensile structural steel at elevated temperatures. Thin-Walled Struct 98:169-176

Zhao MS, Chiew SP (2013) Post-fire mechanical properties of heat-treated high strength steel. In: Proceedings of 10th Pacific structural steel conference (PSSC 2013), pp 562-567 